Article

\title{
Transient and Persistent Efficiency and Spatial Spillovers: Evidence from the Portuguese Wine Industry
}

\author{
Samuel Faria *D, Sofia Gouveia, Alexandre Guedes and João Rebelo
}

check for

updates

Citation: Faria, Samuel, Sofia Gouveia, Alexandre Guedes, and João Rebelo. 2021. Transient and Persistent Efficiency and Spatial Spillovers:

Evidence from the Portuguese Wine Industry. Economies 9: 116. https:// doi.org/10.3390/economies9030116

Received: 9 June 2021

Accepted: 13 August 2021

Published: 18 August 2021

Publisher's Note: MDPI stays neutral with regard to jurisdictional claims in published maps and institutional affiliations.

Copyright: (c) 2021 by the authors. Licensee MDPI, Basel, Switzerland. This article is an open access article distributed under the terms and conditions of the Creative Commons Attribution (CC BY) license (https:// creativecommons.org/licenses/by/ $4.0 /)$.
Department of Economics, Sociology and Management (DESG), Centre for Transdisciplinary Development Studies (CETRAD), University of Trás-os-Montes and Alto Douro (UTAD), Quinta de Prados, 5001-801 Vila Real, Portugal; sgouveia@utad.pt (S.G.); aguedes@utad.pt (A.G.); jrebelo@utad.pt (J.R.)

* Correspondence: samuelf@utad.pt; Tel.: +351-91-8626-418

\begin{abstract}
This paper investigates the presence of spatial spillovers in firms' productive (in)efficiency. For this purpose, a spatial stochastic frontier model is specified and estimated, accounting for spatial dependence and persistent and transient (in)efficiency. This approach is applied to a panel dataset from 2014 to 2019 of Portuguese wineries. Apart from the traditional input and output quantities used in the estimation of a production function, the novelty of this study is the inclusion of information on the firms' exact location, which allows incorporating the neighboring dependence in the productive efficiency analysis. Empirical findings show that despite the Portuguese wineries' technological positive dependence on spatial closeness for both inputs and outputs, the geographic closeness is not strong enough to provide overall productive efficiency gains.
\end{abstract}

Keywords: location; spatial econometric analysis; panel data; wineries; transient and persistent efficiency

JEL Classification: C23; D22; L25; L66

\section{Introduction}

During the last four decades, the globalization of supply chains and free international trade provided the basic conditions for strong competition among firms, industries, and regional economic systems. However, despite the open global economic environment, local and agglomeration externalities are also deemed critical to competitive advantage (Porter 2000). Therefore, to survive and to be competitive, firms should be innovative and improve their efficiency over time (persistent) to achieve the benchmark, or catchup effect, as well as to have time-varying (transient) efficiency in the use of productive resources, with geography and location playing important roles (Martínez-Victoria et al. 2019). The benchmark of business performance, measured by the relationship between inputs and outputs, calls for the analysis of firms' productive efficiency ${ }^{1}$, a topic that has been receiving great attention from scholars, namely with the development of stochastic frontier analysis (SFA), which was first introduced by Aigner et al. (1977) and Meeusen and Van den Meeusen and Broeck (1977). SFA models have been applied with different specifications and assuming distinct distribution and temporal behavior assumptions of the error component, which is interpreted as being the inefficiency term (e.g., Kumbhakar et al. 2015; Greene 2008).

Benefiting from the availability of panel data and the potential to incorporate firmlevel heterogeneity in the econometric analysis, in the last decade, the SFA methodology proposed the decomposition of the productive (in)efficiency level between a transient (timevarying or short-term) component, reflecting how managers employ the inputs compared to the best practice, and a persistent (long-term) component (i.e., structural changes that occur over time, similar to all firms) (Kumbhakar et al. 2014; Alem 2018; Haini 2020). This separation allows for analyzing how (if at all) managerial decisions, regulation processes, 
and industry-wide policies translate into efficiency gains, thereby providing key insights into the development of strategies toward firms and industry competitiveness.

Moreover, firms' activities are interdependent on neighboring productive activities due to regional clustering factors such as externalities, input-output networks, research and development entities, ease of knowledge and spin-off transfer, promotion of imitation, and technological innovation (Martínez-Victoria et al. 2019; Pede et al. 2018). Thus, the behavior and performance of firms are likely to correlate with their geographical distance, calling for the use of spatial models. Policies based on findings from non-spatial models may risk resulting in suboptimal policy outcomes with consequences for the productive efficiency (Kutlu and Nair-Reichert 2019).

Although the neighboring dependency factors can impact firm efficiency, spatial spillovers have been scarcely included in the efficiency analysis in the efficiency literature (Haini 2020). To address this drawback, the spatial SFA model, based on panel data and considering both geographical location and firm heterogeneity, seems to be particularly appropriate, since it allows for controlling transient factors (Vidoli et al. 2016) and productivity and technological spillovers (Zhao et al. 2020). Thus, the analysis of the neighboring effect of firms' geographical locations on their levels of productive efficiency occurs simultaneously, either with the decomposition of these into structural or long-term characteristics (persistent efficiency) and managerial failures or short-term characteristics (transient efficiency). The assumption of heterogeneity in firms (random firm effects) as well as events outside a firm's control (statistical noise) continues to be a topic that deserves further research, namely when applied to industries where the spatial component is relevant. This is particularly pertinent for robustness and validation of the approach, as well as to support decision making by managers and other stakeholders. This paper is framed and developed in this perspective using a panel dataset of Portuguese wineries.

The wine industry seems to be a good example of an internationally competitive industry where production efficiency is contingent on the geographical location, specifically in the case of the so-called Old World countries, namely France, Italy, Spain, and Portugal, in which wine has strong connections with regional and national cultural heritage (Ugaglia et al. 2019). These interrelations are conveyed, for instance, in communication loops between neighboring producers, regarding their production and marketing decisions and practices, the use of new technologies, and the flow of knowledge, which stress the importance of a firm location.

Moreover, globalization paved the way for significant changes in the wine industry worldwide. New World countries, such as the US, Australia, Argentina, Chile, and South Africa, entered the market 40 years ago, benefiting from the availability of inputs and economies of scale, which determined an increase in their market share and a "catch up" process (Morrison and Rabellotti 2017). This threatened the industry's dominance by the traditional countries (Cusmano et al. 2010), who faced rising challenges due to increased competition, changes in consumer behavior, and growing environmental and public health concerns. Therefore, to tackle such challenges and maintain and reinforce competitiveness, traditional producers seek to maximize their resources (productive efficiency) and to develop collective innovative regional strategies and know-how sharing to gain a collective added value advantage through spillover effects (Rebelo and Caldas 2013).

Currently, research in the wine industry has shown that spatial spillovers are likely to be present (Outreville 2016) and influence firms' performance (Vidoli et al. 2016). Additionally, it has been shown that existing geographical clusters influence productive efficiency (Bravo-Ureta et al. 2020), but it remains unclear how firms are affected (efficiency) by spatial spillovers and particularly how these spillovers occur over time (short- and long-run efficiencies). Thus, this paper can provide useful insights into decision making by firm managers, interprofessional organizations, and public entities not only to improve competitiveness through the adoption of the technology's best practice in the wine industry, but also as a benchmark for other industries, namely agro-food, where the spatial component is an important issue. 
To the best of our knowledge, this is the first time that the productive efficiency of wineries has been computed using a model that benefits from a panel dataset and considers the spatial effects, disaggregating transient, and persistent efficiency. The remainder of the paper includes Section 2, which lays out the theoretical and applied framework; Section 3, which provides an overview of the Portuguese wine industry and data used; Section 4, which presents and discusses the econometric results; and Section 5, which provides the concluding remarks.

\section{Methodology}

Measuring firms' productive efficiency is critical to design the best entrepreneurial strategies and to define policy measures that induce spatial spillovers to generate overall productive efficiency and competitiveness gains. This requires the computation of the productive efficiency in a stochastic environment. To address these issues, the SFA framework has been used. This approach is based on the assumption that there is a reachable efficient production, which therefore implies the specification ${ }^{2}$ of a production function (Kumbhakar et al. 2015) and a panel data SFA model specification that captures firm heterogeneity in the same industry. This is attained by the following production function:

$$
\begin{gathered}
y_{i t}=\alpha+x_{i t}^{\prime} \beta+\varepsilon_{i t}, \quad i=1, \ldots, N ; t=1, \ldots, T \\
\varepsilon_{i t}=v_{i t}-u_{i}
\end{gathered}
$$

where $y_{i t}$ is the output for the firm $i$ in the year $t$ and $x_{i t}^{\prime}$ denotes a vector of the inputs. The $\beta$ stands for the vector of the technological parameters associated with each input. The composed error term $\varepsilon_{i t}$ is then the sum of an idiosyncratic disturbance $v_{i t}$ (which is the typical measurement and statistical error), and $u_{i}$ is the term that represents a firm's productive inefficiency, with $v_{i t}$ and $u_{i}$ assumed to be independents, each of which is identically distributed (IID).

The SFA usually relies on the two-step maximum likelihood (ML) method, where first the parameters are estimated for the model, and then the inefficiency component is measured through the mean of the conditional distribution, depending on the inefficiency component and the assumptions of the conditional distribution (e.g., Kumbhakar et al. 2018). The estimation of the firms' productive (technical) efficiency (TE) is usually obtained by the Jondrow et al. (1982) method.

Over the last decade, benefiting from panel data availability, research in the SFA field has evolved toward the decomposition of the inefficiency term. Following the development of new assumptions of the regression error term and estimation techniques, the panel data SFA models have been aggregated into four time generations (Kumbhakar et al. 2014): (1) models in which inefficiency is time- and unit-invariant (Battese and Coelli 1988; Pitt and Lee 1981); (2) models that allow for time-varying inefficiency (Battese and Coelli 1992; Kumbhakar 1990); (3) models that specify unit-specific effects and time-varying inefficiency (Battese and Coelli 1995; Greene 2005); and (4) models that separate unit-specific effects and time-varying inefficiency into persistent and transient inefficiency (Kumbhakar et al. 2014; Kumbhakar and Heshmati 1995). Regarding the latest generation, the focus is on the decomposition of the inefficiency term into short-term (transient) and long-run (persistent) (Kumbhakar et al. 2015; Colombi et al. 2011) (i.e., into the firm's internal strategic inefficiency and managerial weaknesses on one hand, and into the systematic and intrinsically inefficient aspects of production (such as firm location, supply-chain access, or clustering effects) on the other).

Supported by Kumbhakar et al. (2014), the SFA model with a four-error component for panel data is specified as

$$
y_{i t}=\alpha_{0}+f\left(x_{i t} \beta\right)+\mu_{i}+v_{i t}-\tau_{i}-u_{i t}
$$




$$
\begin{aligned}
& v_{i t} \sim N\left(0, \sigma_{v}^{2}\right) \\
& u_{i} \sim N^{+}\left(0, \sigma_{u}^{2}\right) \\
& \tau_{i} \sim N^{+}\left(0, \sigma_{\tau}^{2}\right)
\end{aligned}
$$

where $\mu_{i}$ identifies the random effects, $v_{i t}$ is statistical noise, and $\tau_{i}$ and $u_{i t}$ are the persistent (PTE) and transient (TTE) inefficiency terms, respectively. Thus, the point estimates of productive inefficiency are given by

$$
\begin{gathered}
P T E=\exp \left(-\hat{\tau}_{i}\right) \\
T T E=\exp \left(-\hat{u}_{i t}\right)
\end{gathered}
$$

in which $\hat{\tau}_{i}$ and $\hat{u}_{i t}$ are estimated through the Jondrow et al. (1982) method.

Regarding the spatial effects, an overview of the panel data spatial econometric models can be found in Astuti et al. (2020). Briefly, the Spatial Autoregressive Model (SAR) specifies the existence of spatial effects in the dependent variable, while the Spatial Error Model (SEM) specifies their existence in the error term. Additionally, the Spatial Durbin Model (SDM) allows identifying spatial effects in the dependent variable as well as in the regressors. Thus, to ascertain the role of geographical location or spatial proximity throughout the whole production technology (i.e., output and inputs), the SDM (which nests both the SAR and SEM models) is the appropriate model (Astuti et al. 2020; Haini 2020), with

$$
y_{i t}=\rho W_{i j} y_{i t}+x_{i t} \beta+\theta W_{i j} x_{j t} \beta+\varepsilon_{i t}
$$

where $W$ stands for the spatial weighted matrix $(n * n)$, which is included in the model, interacting with both the output and inputs.

The Spatial Stochastic Frontier Analysis (SSFA) approach emerged in the last decade and aims to merge the SFA methodology within the spatial econometrics framework (Barrios and Lavado 2010; Areal et al. 2012; Fusco and Vidoli 2013). Depending on the distributional assumptions for both the inefficiency term and the spatially weighted matrix (SAR, SEM, or SDM specifications), any existing specification can be adapted to the SSFA methodology. Historically, Druska and Horrace (2004) applied SSFA first using the SEM structure and estimating the model by the method of moments. Similarly, Fusco and Vidoli (2013) also used the SEM structure, although they estimated the model by the maximum likelihood methods. Authors such as Glass et al. (2016) and Tsukamoto (2019) introduced and applied SSFA with an SAR structure. Recently, Glass and Kenjegalieva (2019) and Haini (2020) considered the SDM specification, which can be generically defined as

$$
y_{i t}=\alpha_{0}+\rho W_{i j} y_{i t}+x_{i t} \beta+\theta W_{i j} x_{j t} \beta+\mu_{i}+v_{i t}-\tau_{i}-u_{i t}
$$

which is the combination of Equation (4) with the error term consisting of a four-component error as in Equation (2). This specification can be estimated through a multi-step procedure as in the work of Kumbhakar et al. (2014) or through a more efficient simulated maximum likelihood estimation (MLE) method, as in the work of Filippini and Greene (2015) and Colombi et al. (2014). The multi-step procedure involves easier computation and provides consistent estimates, which justify the extensive use in the literature (e.g., Agasisti and Gralka 2019; Acosta and Santos-Montero 2019), as is the case for this paper.

In the context of the wine industry, former research suggests that the geographic location and spatial dependence are likely to be present in both the input and output factors (Pokharel 2018). Vidoli et al. (2016) stated that specific technological patterns ought to be influenced by an intangible factor, which can be interpreted as the local business climate, concluding that spatial proximity does not necessarily generate knowledge spillovers. Outreville (2016) found spatial spillovers in the wine industry and that the location can determine the level of efficiency of wine firms. Additionally, Canello and Vidoli (2020) observed the existence of geographical clusters. Bravo-Ureta et al. (2020), focusing on grape growers, showed that the geographic location influences productive efficiency. 
Efficiency analysis in the wine industry ${ }^{3}$ is limited to few contributions, relying on the Data Envelopment Approach, a non-parametrical method (Aparicio et al. 2020; Marta-Costa et al. 2017; Tóth and Gá 2014; Urso et al. 2018) and in the SFA methodology (Bravo-Ureta et al. 2020; Conradie et al. 2006; Kallas and Lambarra 2010; Moreira et al. 2011; Vidoli et al. 2016). In the SFA branch, the literature has been demonstrating that there are constant returns to scale (Moreira et al. 2011), and factors such as size, labor, and capital intensity affect a firm's ability to reach its maximum potential production (efficiency). Kallas and Lambarra (2010) focused on how the decision to enter or exit the industry is related to a firm's efficiency, using the total turnover as the output and labor, the cost of raw materials, and employed capital as the inputs. Vidoli et al. (2016) referenced that heterogeneity (inefficiency) in performance may occur due to intangible local factors, hinting at spatial dependence between firms.

In addition, research within the SSFA framework in the wine industry is quite scarce, with a few articles developing and applying such a methodology. Fusco and Vidoli (2013) were pioneers in developing a specification that allows the spatial heterogeneity to be correlated with the error (inefficiency) term. Vidoli et al. (2016) used this specification with a dataset of Italian wine (grape) producers to evaluate the role of intangible factors influencing efficiency. Canello and Vidoli (2020) employed a geographically weighted panel SFA with Italian farms to identify geographical clusters and their responses to institutional shocks. This shortage highlights the need for further research in the line of this paper, which enforces a new application of the SSFA method with the SDM specification in the wine industry.

\section{Research Setting}

\subsection{The Portuguese Wine Industry}

In light of the adaptation and reaction to the catch up process triggered by the latecomers (Morrison and Rabellotti 2017) (i.e., the New Wine Countries (NWC)), in the group of traditional European or Old Wine Countries (OWCs), Portugal arises as an interesting case to study since it includes most of the characteristics of a traditional OWC, namely demarcating production by regions according to the characteristics of the terroir (Hogg and Rebelo 2018), also being a relevant and competitive player in the international market. Portugal is one of the larger wine producers and exporters in the EU, being fifth in 2019 (Instituto da Vinha e do Vinho 2019) with an average annual growth of wine exports from 2000 to 2016 of 3\% (Macedo et al. 2019), which enhanced the competitiveness of the Portuguese wine industry in the international market.

Despite Portugal's ancient wine tradition and heritage, particularly with Port wine, which has been exported for more than two centuries (Guedes and Rebelo 2019), the development of the Portuguese wine industry is relatively new, mainly driven by Portugal's entry into the European Union (in 1986). Before that, the industry was characterized by small producers, which had few competitive structures and did not engage in exporting activities. Thus, the Portuguese wine industry lagged behind its international competitors (Lains 2018). After joining the EU, a set of initiatives toward the promotion of Portuguese wines were carried out by interprofessional associations and public policies, benefiting from the openness of new international markets. This allowed wineries (especially those of a larger size) to enter these markets with different types of wine, brands, and origins, thus building a collective reputation for the Portuguese wines. Consequently, the industry accelerated both horizontal and vertical integration (Macedo et al. 2019) and innovation (Rebelo and Muhr 2012; Rebelo and Caldas 2013), which increased international competitiveness, supported by technological progress and improving productive efficiency.

Benefiting from spillover effects, spinoffs, cooperation, and joint promotion in third markets (out of the European Union), the market structure that emerged is typical of monopolistic competition, prevailing small- and medium-sized enterprises (SMEs), vertical (e.g., vintage, grand reserve, and reserve) and horizontal (e.g., wine appellation of origin or 
color) product differentiation and freedom to enter and exit the market (Hogg and Rebelo 2018; Macedo et al. 2019).

Official data from the Banco de Portugal ${ }^{4}$ (Portuguese central bank) shows that in 2019, there were 966 licensed wineries in the country. Moreover, the industry is predominantly composed of small family-owned firms ( $99.69 \%$ of firms can be classified as SMEs), as is typical of a monopolistic competitive structure. Older firms (over 20 years of activity) account for $80.93 \%$ of the total industry turnover, which shows the challenging environment for new entrants to obtain market share. Portugal's wine industry is characterized by strong historical ties, heterogeneity regarding firm size, public regulation out of the firm manager's control, and geographic diversity, illustrated by its 12 demarcated wine regions (Figure 1). These are scattered throughout the country, and each has a restricted regulatory framework for grape production and wine typology to sell, which may constrain spatial spillovers even between neighboring wineries.

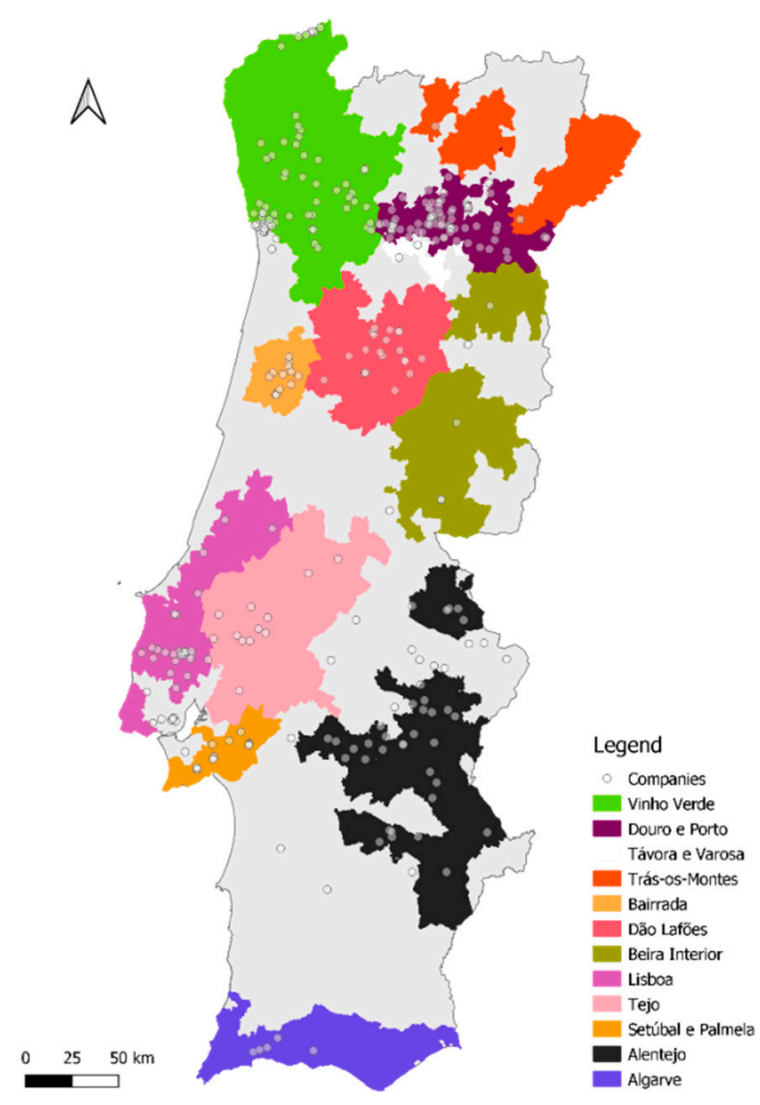

Figure 1. Geographical distribution of wine regions in Portugal. Source: own elaboration.

It is within this context that Equation (5) seems to fit the production technology of Portuguese wineries well, being well expressed by the Spatial Stochastic Frontier Model (SFSDM). Therefore, the specification of the SFSDM model used in this paper is defined by

$$
y_{i t}=\alpha_{0}+\eta_{1} t+\eta_{2} t^{2}+\rho W_{i j} y_{i t}+x_{i t} \beta+\theta W_{i j} x_{j t} \beta+\mu_{i}+v_{i t}-\tau_{i}-u_{i t}
$$

Like in Equation (5), $\alpha_{0}$ is the constant, and $\eta_{1} t+\eta_{2} t^{2}$ reflects the time trend ${ }^{5}$ to capture the technological progress in the regression. The parameters $\rho$ and $\theta$ assess the spatially weighted influence of both the dependent variable and the exogenous inputs of the production function. Moreover, $\mu_{i}$ denotes random effects, $v_{i t}$ is the statistical noise, and $\tau_{i}$ and $u_{i t}$ are the persistent and transient inefficiency terms, respectively. $W_{i j}$ identifies the spatial weighted matrix, which measures the distances between firms by applying the inverse distance weighting (IDW) method. To calculate a value for any unmeasured location, IDW takes into consideration two factors: the search radius and the inverse 
distance weight power value. The computed values closest to the estimated location have more of an effect on the predicted value and therefore greater weights than those that are remoter.

\subsection{Data}

To compute the productive efficiency, technological homogeneity needs to be assumed. To fulfill this theoretical condition, the research only considers firms that are included in the group $^{6}$ that produces and sells wine (wineries, from the vinification of their own produced grapes or buying from other grape growers).

Regarding the specification of the production function of the wine industry, the output is typically measured by the production of grapes (Vidoli et al. 2016; Outreville 2016) or turnover (Martínez-Victoria et al. 2019). Typically, SFA research uses labor and capital (Vidoli et al. 2016; Canello and Vidoli 2020) as inputs or financial indicators such as the value of fixed assets, labor costs, material costs, and investments (Martínez-Victoria et al. 2019).

Following the Portuguese accounting nomenclature, we considered the total annual turnover as the output, while the inputs were (1) the number of employees as a proxy for the labor input; (2) the value of the fixed assets' depreciation and amortizations as a proxy for the capital input; (3) the cost of raw materials, which includes the cost of grapes, bottles, and other materials included in the final product; and (4) the cost of supplies and services, which includes goods and services provided by suppliers required for the firm's production such as fuel, electricity, annual repairing of fixed assets, marketing, and communication costs.

The data source was the annual official fiscal reports (Informação Empresarial Simplificada (IES)) of firms included in the 11,021 NACE codes (statistical classification of economic activities of the EU), provided by Informa Dun \& Bradsheet. A random sample of 304 firms was achieved, which offered a representation of nearly $30 \%$ of the firms licensed. The period covered from 2014 to 2019 , which was the longest time series with the available data for all variables, resulting in a final sample of 1824 observations. All variables were at constant prices, with 2015 being the base year (the deflator of the GDP was retrieved from the World Development Indicators database and used to deflate the variables). To linearize the values, natural logarithms were taken for all considered variables in subsequent analysis and estimations. Table 1 displays the descriptive statistics of the output turnover and inputs used in the estimation of Equation (5).

Table 1. Descriptive statistics.

\begin{tabular}{ccccccc}
\hline Variable & Unit & Definition & Mean & Std. Dev. & Min & Max \\
\hline Turnover & $10^{3}$ Euro & Value of total sales & 2751.97 & 9995.55 & 0.14 & $137,477.94$ \\
Employees & Number & Number of paid employees in the current year & 14.59 & 39.71 & 1 & 638 \\
Depreciations & $10^{3}$ Euro & Value of capital depreciations and & 144.97 & 364.03 & 0.04 & 5209.47 \\
CRM & $10^{3}$ Euro & amortizations & 1488.94 & 4706.26 & 0.02 & $41,618.24$ \\
CSS & $10^{3}$ Euro & Cost of raw materials & 548.67 & 2529.97 & 0.94 & $40,125.88$ \\
\hline
\end{tabular}

The mean turnover (output) was EUR 2751.971, with a standard deviation of EUR 9995.552 (a variation coefficient of 363\%), which confirmed the high industry heterogeneity characteristic of monopolistic competitive structures.

The geographical distribution of firms and size measured by the employees variable (Figure 2) shows a dispersed location of firms across the country, representing the spatial heterogeneity of the industry. The Douro and Porto, Lisboa, and Alentejo regions host the highest number of and larger firms (in terms of the number of employees). 


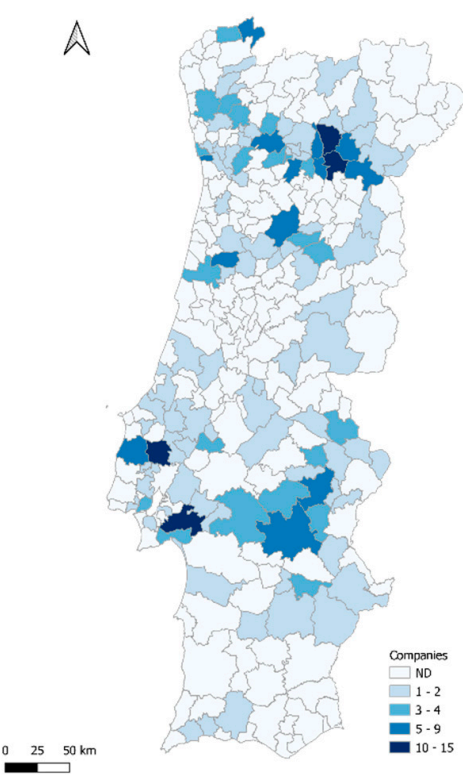

(a)

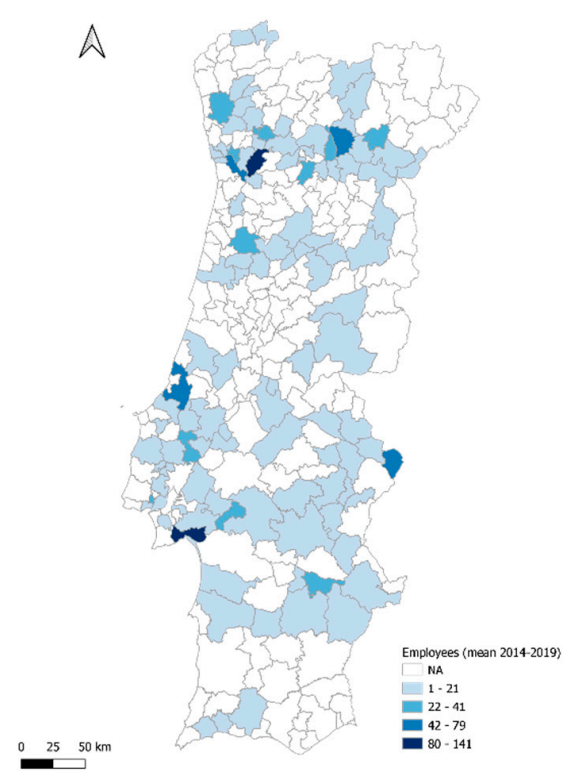

(b)

Figure 2. Geographical distribution of firms and size (2014-2019). Source: own elaboration. (a) Number of firms. (b) Mean number of employees.

Even though it appears to be a tendency for larger firms to agglomerate near their competitors, it is not easy to identify regional clusters. Since in the Portuguese wine industry larger firms tend to outperform smaller firms (Faria et al. 2020), this might induce profitable firms tending to be located in the same regions. However, the dispersion of smaller firms throughout the territory does not provide any particular pattern regarding the link between performance and location. To assess the existence of spatial autocorrelation for the annual turnover, Figure 3 highlights a scatterplot for Moran's I ${ }^{7}$. This index reflects a positive-albeit small-spatial correlation for the mean of the annual turnover of the sample. Thus, only the computation and comparison of efficiency scores between firms can provide insights on the role of a firm's location in productive performance.

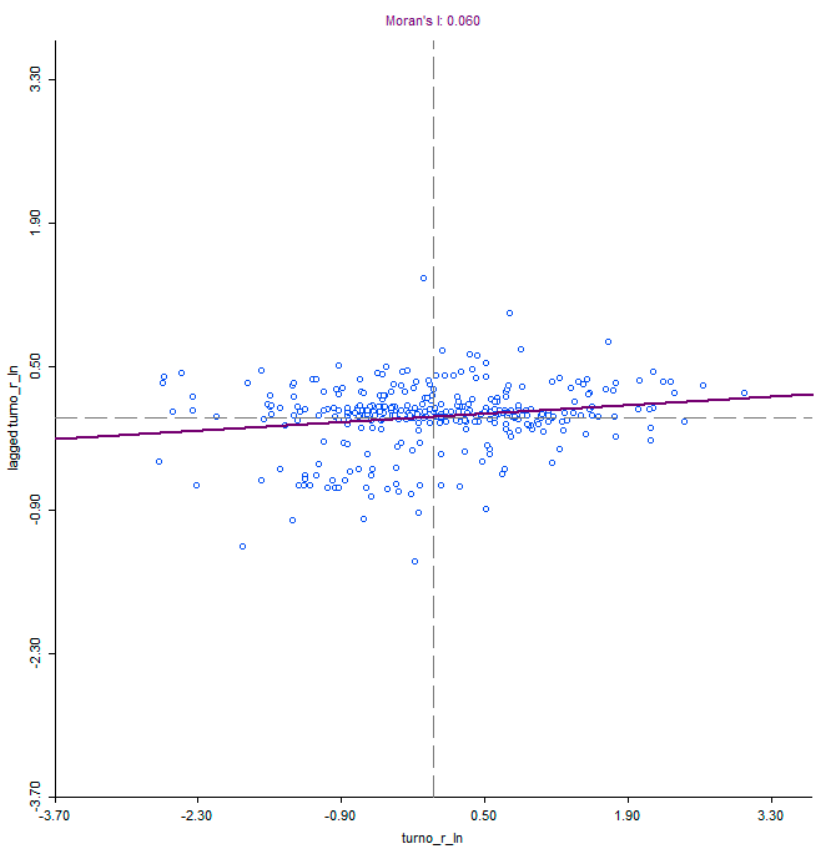

Figure 3. Scatterplot for Moran's I (mean turnover, 2014-2019). Source: own elaboration. 


\section{Results and Discussion}

Based on the likelihood ratio (LR) test, the translog production function fit the data better than the Cobb-Douglas production function. ${ }^{8}$ Thus, we proceeded with the specification of a translog production function, which allowed us to relax the assumption of constant input elasticities. Subsequently, the presence of panel effects was tested against the pooled regression through the Breusch and Pagan (1980) Lagrange multiplier (LM) test, presenting a value of $\left(\mathrm{Chi}^{2}(1)=853.70^{* * *}\right)$, which allowed us to conclude that the panel effects were present and the panel data models ought to be estimated. Moreover, given the assumptions for the inefficiency term, the use of fixed effects could provide biased results, as it would determine a correlation between the fixed effect term and the idiosyncratic error term (Haini 2020). Thus, to ensure that the assumptions regarding inefficiency held, the random effects arose as the most suitable estimation.

Given this, the random effect model was estimated through $\mathrm{MLE}^{9}$, which signaled the absence of spatial autocorrelation in the error term, whereas the Moran's I value for the global spatial correlation in the RE model $(-0.2358)$ suggests that there was a random spatial process (i.e., an unidentifiable pattern in the firms' spatial distribution).

Additionally, the LM test for the presence of spatial autocorrelation in the spatial lagged dependent variable suggests it might have occurred through an AR(1) process (i.e., the values of production of neighboring firms in the previous period influenced the current production of a firm). Moreover, the LM test pointed to the presence of spatial autocorrelation, confirming that generically, neighboring firms' production influenced a firm's current production level. Following this benchmark result, the SAR model was estimated accordingly to assess the existence of spatial effects in the dependent variable. The significance of rho, associated with the lagged dependent variable (turnover), shows that the AR(1) process identified was of low statistical significance, even though it could not be ignored for robust estimations.

Regarding the presence of spatial effects in the regressors, the SEM model was estimated. The results were significant at the $5 \%$ level for lambda (i.e., allowing confirmation of the presence of spatial effects on the vector of the regressors).

The estimation results of the RE, SAR, and SEM models allowed for identifying spatial autocorrelation of the lagged dependent variable, as well as spatial autocorrelation in the regressors, which called for the estimation of the Spatial Durbin Model (SDM). In this model, the statistical significance of $\theta$ confirmed the presence of spatial dependence on the input factors. However, the non-significance of $\rho$ suggests that the previously identified autocorrelation in the dependent variable was not strong enough to be statistically significant in this specification in line with the SAR results.

Finally, based on the results of the previous models, and to assess a firm's productive efficiency and its decomposition in transient and persistent components, the Spatial Stochastic Frontier Durbin Model (SSFDM) was used for estimation.

Table 2 displays the model estimation results of the RE (for benchmark), SAR, SEM, SDM, and finally the SSFDM, which is the model of greatest interest in this research. Generically, the significance of the parameters of the translog function improved from the RE specification to the SAR and SEM specifications, which suggests that capturing the spatial effects improved the level of explanation of the estimations. 
Table 2. Estimation results.

\begin{tabular}{|c|c|c|c|c|c|c|}
\hline \multirow{3}{*}{ Variable } & \multirow{3}{*}{$\begin{array}{c}\text { Model } 1 \\
\text { RE } \\
\text { Coeff. }\end{array}$} & \multirow{3}{*}{$\begin{array}{c}\text { Model } 2 \\
\text { SAR } \\
\text { Coeff. }\end{array}$} & \multirow{3}{*}{$\begin{array}{c}\text { Model } 3 \\
\text { SEM } \\
\text { Coeff. }\end{array}$} & \multirow{3}{*}{$\begin{array}{c}\text { Model } 4 \\
\text { SDM } \\
\text { Coeff. }\end{array}$} & \multicolumn{2}{|c|}{ Model 5} \\
\hline & & & & & \multicolumn{2}{|c|}{ SSFDM } \\
\hline & & & & & Coeff. & Spatial Lag \\
\hline LnEmployees & $\begin{array}{l}0.0842 * \\
(0.0491)\end{array}$ & $\begin{array}{c}0.0534 \\
(0.0330)\end{array}$ & $\begin{array}{l}0.0551 * \\
(0.0330)\end{array}$ & $\begin{array}{l}0.0623 * \\
(0.0357)\end{array}$ & $\begin{array}{l}0.0647^{* *} \\
(0.0330)\end{array}$ & $\begin{array}{l}-0.0045 \\
(0.0121)\end{array}$ \\
\hline LnDepreciations & $\begin{array}{c}0.1793^{* * *} \\
(0.0367)\end{array}$ & $\begin{array}{c}0.1075^{* * *} \\
(0.0261)\end{array}$ & $\begin{array}{c}0.1081^{* * *} \\
(0.0260)\end{array}$ & $\begin{array}{c}0.1050 * * * \\
(0.0281)\end{array}$ & $\begin{array}{c}0.1020^{* * *} \\
(0.0259)\end{array}$ & $\begin{array}{c}0.0129 \\
(0.0085)\end{array}$ \\
\hline LnCSS & $\begin{array}{c}0.6191 * * * \\
(0.0494)\end{array}$ & $\begin{array}{c}0.4847^{* * *} \\
(0.0329)\end{array}$ & $\begin{array}{c}0.4839 * * * \\
(0.0329)\end{array}$ & $\begin{array}{c}0.4964^{* * *} \\
(0.0355)\end{array}$ & $\begin{array}{c}0.4800^{* * *} \\
(0.0328)\end{array}$ & $\begin{array}{c}-0.0071 \\
(0.0034)\end{array}$ \\
\hline LnCRM & $\begin{array}{c}0.3211^{* * *} \\
(0.0284)\end{array}$ & $\begin{array}{c}0.4932 * * * \\
(0.0177)\end{array}$ & $\begin{array}{c}0.4930^{* * *} \\
(0.0177)\end{array}$ & $\begin{array}{c}0.4940^{* * *} \\
(0.0193)\end{array}$ & $\begin{array}{c}0.4995^{* * *} \\
(0.0178)\end{array}$ & $\begin{array}{c}0.0033 \\
(0.0044)\end{array}$ \\
\hline LnEmployees $^{\mathrm{x}}$ & $0.2041^{* * *}$ & $0.1162^{* * *}$ & $0.1159 * * *$ & $0.1098^{* * *}$ & $0.1268^{* * *}$ & 0.0087 \\
\hline LnDepreciations & $(0.0379)$ & $(0.0377)$ & $(0.0377)$ & $(0.0405)$ & $(0.0374)$ & $(0.0092)$ \\
\hline LnEmployees ${ }^{\mathrm{x}}$ LnCSS & $\begin{array}{c}-0.3184^{* * *} \\
(0.0659)\end{array}$ & $\begin{array}{c}-0.3472 * * * \\
(0.0577)\end{array}$ & $\begin{array}{c}-0.3478^{* * *} \\
(0.0576)\end{array}$ & $\begin{array}{c}-0.3517^{* * *} \\
(0.0619)\end{array}$ & $\begin{array}{c}-0.35111^{* * *} \\
(0.0571)\end{array}$ & $\begin{array}{c}-0.0241 \\
(0.0137)\end{array}$ \\
\hline LnEmployees ${ }^{\mathrm{x}} \mathrm{CRM}$ & $\begin{array}{c}0.1069 * * * \\
(0.0300)\end{array}$ & $\begin{array}{c}0.1145^{* * *} \\
(0.0289)\end{array}$ & $\begin{array}{c}0.1157 * * * \\
(0.0289)\end{array}$ & $\begin{array}{c}0.1595^{* * *} \\
(0.0308)\end{array}$ & $\begin{array}{c}0.1271^{* * *} \\
(0.0286)\end{array}$ & $\begin{array}{l}-0.0009 \\
(0.0087)\end{array}$ \\
\hline LnDepreciations ${ }^{\mathrm{x}}$ LnCSS & $\begin{array}{c}-0.0574^{* *} \\
(0.0261)\end{array}$ & $\begin{array}{c}-0.1318^{* * *} \\
(0.0248)\end{array}$ & $\begin{array}{c}-0.1310^{* * *} \\
(0.0248)\end{array}$ & $\begin{array}{c}-0.1018^{* * *} \\
(0.0271)\end{array}$ & $\begin{array}{c}-0.1063^{* * *} \\
(0.0250)\end{array}$ & $\begin{array}{c}0.0045 \\
(0.0049)\end{array}$ \\
\hline LnDepreciations ${ }^{\mathrm{x}}$ LnCRM & $\begin{array}{l}0.0284^{* *} \\
(0.0120)\end{array}$ & $\begin{array}{c}0.0535 * * * \\
(0.0129)\end{array}$ & $\begin{array}{c}0.0531^{* * *} \\
(0.0129)\end{array}$ & $\begin{array}{l}0.0349 * * \\
(0.0140)\end{array}$ & $\begin{array}{c}0.0370^{* * *} \\
(0.0129)\end{array}$ & $\begin{array}{c}-0.0079 * * \\
(0.0034)\end{array}$ \\
\hline LnCSS $^{\mathrm{x}} \operatorname{LnCRM}$ & $\begin{array}{c}0.1051^{* * *} \\
(0.0198)\end{array}$ & $\begin{array}{c}0.1185^{* * *} \\
(0.0200)\end{array}$ & $\begin{array}{c}0.1182 * * * \\
(0.0200)\end{array}$ & $\begin{array}{c}0.1301 * * * \\
(0.0216)\end{array}$ & $\begin{array}{c}0.1348^{* * *} \\
(0.0200)\end{array}$ & $\begin{array}{l}0.0103 * * \\
(0.0051)\end{array}$ \\
\hline $\mathrm{T}$ & $\begin{array}{c}-0.0013 \\
(0.084)\end{array}$ & $\begin{array}{c}0.0099 \\
(0.0115)\end{array}$ & $\begin{array}{c}0.0099 \\
(0.0115)\end{array}$ & $\begin{array}{c}0.0004 \\
(0.0099)\end{array}$ & $\begin{array}{c}-0.0013 \\
(0.009)\end{array}$ & $\begin{array}{c}0.0008 \\
(0.0024)\end{array}$ \\
\hline $\mathrm{T}^{2}$ & $\begin{array}{c}-0.0220^{* * *} \\
(0.0078)\end{array}$ & $\begin{array}{c}-0.01193 \\
(0.0115)\end{array}$ & $\begin{array}{l}-0.0120 \\
(0.0119)\end{array}$ & $\begin{array}{l}-0.0154 \\
(0.0135)\end{array}$ & $\begin{array}{l}-0.0081 \\
(0.0125)\end{array}$ & $\begin{array}{l}-0.0012 \\
(0.0013)\end{array}$ \\
\hline LnEmployees $^{\dagger}$ & $\begin{array}{c}-0.1723^{* * *} \\
(0.0486)\end{array}$ & $\begin{array}{l}-0.0561 \\
(0.0427)\end{array}$ & $\begin{array}{l}-0.0558 \\
(0.0426)\end{array}$ & $\begin{array}{c}-0.1135^{* *} \\
(0.0459)\end{array}$ & $\begin{array}{c}-0.0710 * \\
(0.0424)\end{array}$ & $\begin{array}{c}0.0063 \\
(0.0117)\end{array}$ \\
\hline LnDepreciations $^{\dagger}$ & $\begin{array}{l}-0.0009 \\
(0.0110)\end{array}$ & $\begin{array}{c}0.0393^{* * *} \\
(0.0110)\end{array}$ & $\begin{array}{c}0.0396^{* * *} \\
(0.0110)\end{array}$ & $\begin{array}{c}0.0378^{* * *} \\
(0.0118)\end{array}$ & $\begin{array}{c}0.0320^{* * *} \\
(0.0109)\end{array}$ & $\begin{array}{c}0.0022 \\
(0.0034)\end{array}$ \\
\hline $\mathrm{LnCSS}^{\dagger}$ & $\begin{array}{c}0.0964^{* * *} \\
(0.0293)\end{array}$ & $\begin{array}{c}0.0761^{* * *} \\
(0.0274)\end{array}$ & $\begin{array}{c}0.0755^{* * *} \\
(0.0274)\end{array}$ & $\begin{array}{l}0.0645^{* *} \\
(0.0297)\end{array}$ & $\begin{array}{l}0.0549 * * \\
(0.0275)\end{array}$ & $\begin{array}{c}0.0015 \\
(0.0052)\end{array}$ \\
\hline $\mathrm{LnCRM}^{\dagger}$ & $\begin{array}{c}-0.0309 * * * \\
(0.0077)\end{array}$ & $\begin{array}{c}-0.0342^{* * *} \\
(0.0071)\end{array}$ & $\begin{array}{c}-0.0343^{* * *} \\
(0.0071)\end{array}$ & $\begin{array}{c}-0.0401^{* * *} \\
(0.0076)\end{array}$ & $\begin{array}{c}-0.0339 * * * \\
(0.0070)\end{array}$ & $\begin{array}{c}0.0004 \\
(0.0019)\end{array}$ \\
\hline$\rho$ & - & $\begin{array}{l}0.0004^{* *} \\
(0.0002)\end{array}$ & - & $\begin{array}{c}0.0002 \\
(0.0007)\end{array}$ & -0.00 & $.0011)$ \\
\hline$\lambda$ & - & - & $\begin{array}{l}0.0003 * * \\
(0.0002)\end{array}$ & & & \\
\hline$\theta$ & & & & $\begin{array}{c}0.6228 * * * \\
(0.0103)\end{array}$ & & \\
\hline$\mu_{i}$ & - & - & & - & 0.7 & \\
\hline$v_{i t}$ & - & - & - & - & 0.5 & \\
\hline Log Likelihood Function & -1344.8401 & -1593.4149 & -1592.4286 & -1722.5970 & -157 & .9469 \\
\hline $\mathrm{R}^{2}$ & 0.8784 & 0.8899 & 0.8662 & 0.8716 & & \\
\hline Wald & $12,921.04^{* * *}$ & $14,573.71^{* * *}$ & $14,576.85^{* * *}$ & $12,153.01^{* * *}$ & 14,878 & $32 * * *$ \\
\hline $\mathrm{F}$ & $646.05^{* * *}$ & $728.69^{* * *}$ & $728.8425^{* * *}$ & $379.7814^{* * *}$ & 464.9 & $72 * * *$ \\
\hline AIC & 0.4670 & 0.4186 & 0.4184 & 0.5138 & 0.5 & \\
\hline $\mathrm{BIC}$ & 0.5021 & 0.4459 & 0.4458 & 0.5676 & 0.5 & \\
\hline
\end{tabular}


Table 2. Cont.

\begin{tabular}{cccccc}
\hline & Model 1 & Model 2 & Model 3 & Model 4 & \multicolumn{2}{c}{ Model 5 } \\
\hline Variable & RE & SAR & SEM & SDM & \multicolumn{2}{c}{ SSFDM } \\
\hline Coeff. & Coeff. & Coeff. & Coeff. & Coeff. & Spatial Lag \\
\hline LM Lag & & & -0.2358 & & -0.0241 \\
LM SAC & $698.0772^{* * *}$ & & & $491.1592^{* * *}$ & 0.0647 \\
& $777.3232^{* * *}$ & & & $843.6141^{* * *}$ & 0.7040 \\
\hline
\end{tabular}

Note: $\rho$ is the parameter associated with the spatial components in both the SAR and SDM specifications, and $\lambda$ denotes the spatial weighted parameter in the error term in the SEM specification. Robust standard errors are reported in brackets. Model 5 includes coefficients for the spatial lag variables. ${ }^{* * *},{ }^{* *}$ and ${ }^{*}$ denote significance at the $1 \%, 5 \%$ and $10 \%$ levels, respectively. ${ }^{\dagger}$ Typically, two main specifications are used: the Cobb-Douglas (CD) and translog production functions (TL). The TL offers more flexibility than the CD, which is usually easier to estimate and works well when elasticities are constant over the sample (Pavelescu 2011).

The non-significance of the parameters of the time trend $\left(t\right.$ and $\left.t^{2}\right)$ in the econometric spatial models shows that there was no presence of technological progress or regression along the period under analysis. Moreover, based on the significance of the parameters $\rho$ $\left(0.0004^{* *}\right), \lambda\left(0.0002^{* *}\right)$, and $\theta\left(0.6228^{* * *}\right)$, it is possible to conclude that there were spatial effects in both the SAR, SEM, and SDM specifications, specifically in the regressors and the error term, which could not be neglected, even if they were of small magnitudes. This means that the production technology of the Portuguese wine industry displays traces of spatial dependence (i.e., the geographic locations of firms can induce spillover effects that affect their production technology). This can be sustained by the fact that the production of wine is particularly influenced by local grape production and competitors' agglomerations, both in supplies and services and in raw materials.

The non-significance in the spatial component in the SSFDM specification suggests that the spatial dependence effects identified in the SAR, SEM, and SDM specifications were transferred to the inefficiency term, which means that the firm location and agglomeration might have impacted the productive efficiency estimates.

Since the coefficients of the SSFDM identified essentially marginal effects (Haini 2020; Pham et al. 2019), the results show that supplies and services and the cost of raw materials displayed the higher marginal effects, which implies that the production function depended mostly on the supply conditions and the firm's ability to transform and commercialize wines. This result seemed to be influenced by limitations on the supply of grapes due to regulations inherent to each demarcated region across the industry, which constituted the main raw material in the production process. However, the sum of the input elasticities at the sample mean (1.1462) was higher than one, which indicated increasing returns to scale and, consequently, the presence of scale economies in the Portuguese wine industry, as the previous literature also identified (Faria et al. 2020; Behmiri et al. 2019).

The spatially weighted regressors showed that there were spatial spillovers in the supplies and services input, thus enhancing its importance toward efficiency. However, the negative sign suggests that agglomeration affected the overall production level, suggesting limitations in access to the supply chain.

To assess the impact of space on productive efficiency, Table 3 includes statistical information (average, standard error, and median) on the transient, persistent, and overall (productive) efficiency provided by the SSFDM model both weighted and not weighted with the spatial effects. 
Table 3. Productive efficiency scores.

\begin{tabular}{ccccc}
\hline & & Transient Efficiency & Persistent Efficiency & Overall Efficiency \\
\hline \multirow{3}{*}{ Spatial Weighted } & Average & 0.6725 & 0.7459 & 0.5136 \\
& Std. Error & 0.1378 & 0.1219 & 0.1523 \\
& Median & 0.6918 & 0.7718 & 0.5301 \\
\hline \multirow{3}{*}{ Spatial Non-Weighted } & Average & 0.7793 & 0.7513 & 0.5880 \\
& Std. Error & 0.0924 & 0.1195 & 0.1196 \\
& Median & 0.7925 & 0.7735 & 0.6083 \\
\hline \multicolumn{2}{c}{ Average Difference } & -0.1069 & -0.0054 & -0.07441 \\
\hline
\end{tabular}

Note: The average difference is the difference between the average of the spatial weighted and non-weighted estimates.

Generically, in the SSFA, transient efficiency, which refers to the short-term or managerial efficiency, spanned from as low as $25.71 \%$ (for the least efficient firm) to as high as $87.65 \%$ (the most efficient firm), with a variation coefficient of $20 \%$. This means that, on average, firms could improve the short-term efficiency by nearly $33 \%$, which called for the implementation of managerial strategies to strengthen and promote productivity gains (i.e., better use of inputs in comparison with the observed best practice represented by the stochastic frontier production).

Persistent efficiency (i.e., long-term efficiency) varied from $69.12 \%$ to $98.96 \%$, with a variation coefficient of $16 \%$. Consequently, firms could, on average, improve their longterm efficiency by nearly $25 \%$. This may reflect that long-term inefficiencies are more likely to be caused by external factors influencing firms' abilities, such as regulatory measures, lacking strong networks, or innovative regional clusters.

The wide range of variations (especially in transient efficiency) reflected appropriately the heterogeneity in the Portuguese wine industry, where a large number of SMEs coexist and compete with a few large firms. Considering the short time span and the rejection of technical progress, the average efficiency scores remained relatively stable over time, hinting that the dynamics of the industry did not change substantially in this period.

The overall efficiency score had a mean of $51.36 \%$ (ranging from as low as $9.08 \%$ to $80.89 \%$ ), with a variation coefficient of $24 \%$, which stresses the need for a large number of firms to improve their use of inputs and establish compatible short- and long-term strategies that can lead to lower dispersion between capabilities and actual production. In terms of overall efficiency, it can be said that firms can (with the observed used inputs) increase their turnover by $49.64 \%$ if all of them adopt the best practices for implementing new technology.

Regarding geographic location, as mentioned above, the Moran's I value indicated that there was a random space in a winery's behavior, allowing us to infer that there were no systematic spatial clusters in the production efficiency indicators, although the spatial relationship may have occurred. These are especially interesting results, as it defies what one could expect from a traditional wine country with centuries of producing experience. The non-existence of clear agglomeration patterns could therefore be explained since, despite its ancient history in production, the development, openness to international markets, and competitive environment of the Portuguese wine industry was only pursued in the last four decades (following Portugal's entrance into the EU) (Lains 2018). Therefore, for a better understanding of the results, the three SFSDM productive efficiency indices were charted, providing the maps shown in Figure 4. 


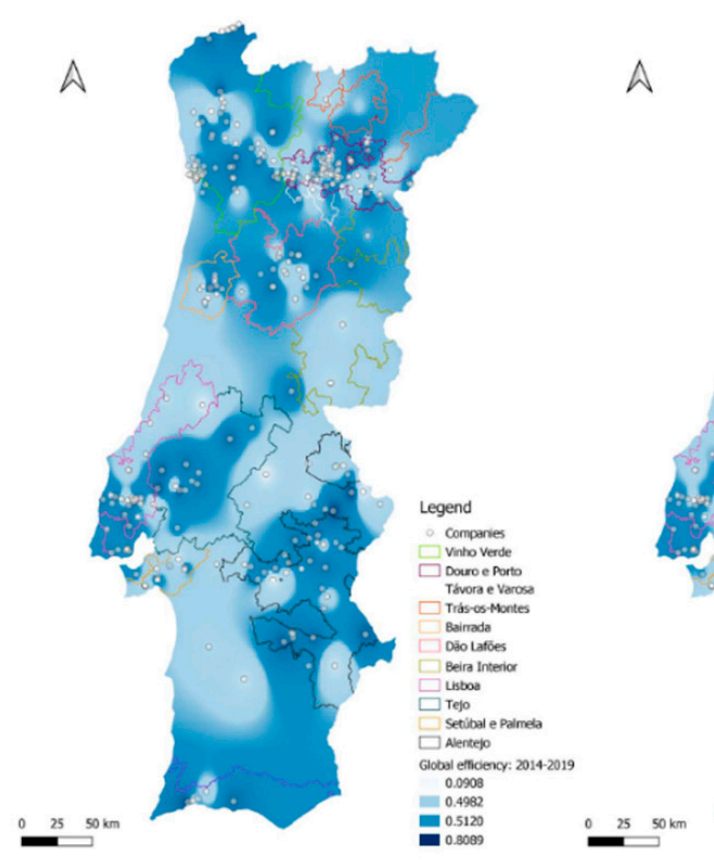

(a)


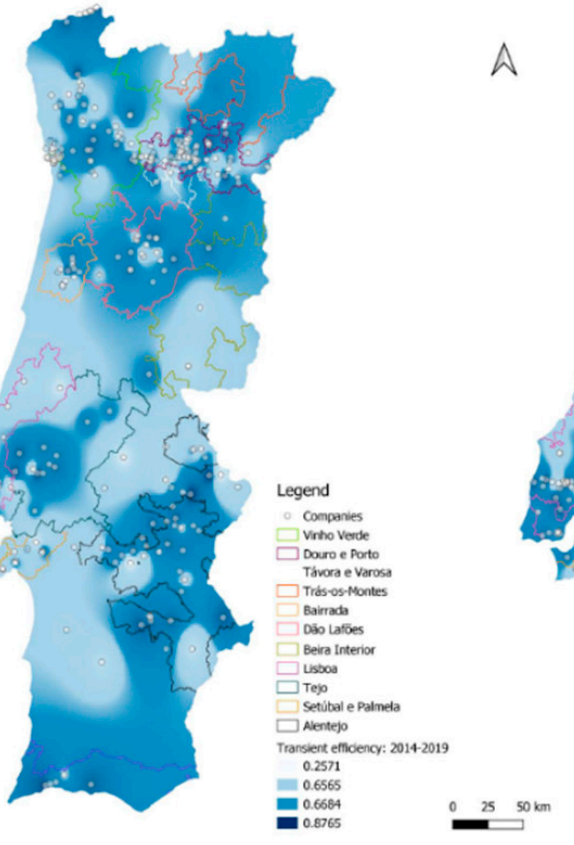

(b)

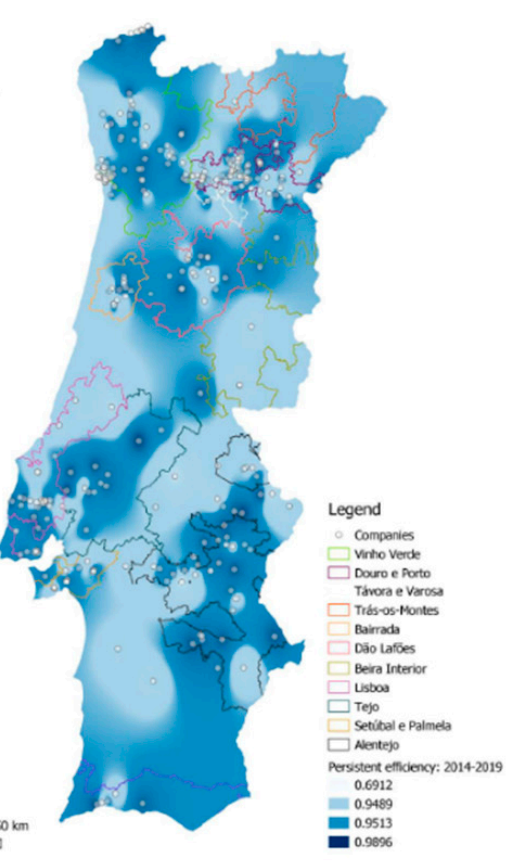

(c)

Figure 4. Spatial distribution of efficiency scores (SFSDM). Source: own elaboration. (a) Global efficiency. (b) Transient efficiency. (c) Persistent efficiency.

A map overview allowed for checking that there was heterogeneous dissemination of scores across the country, highlighting regions in which firms could achieve higher levels of efficiency and regions in which the firms' abilities were capped. Based on the spatial interpolation, which represents score values for every point throughout mainland Portugal's extent, spatial dependence through the transitional areas (shaded values represent spatial dependence) was illustrated, confirming that neighboring relations influenced the ability of firms to reach their maximum potential (or the inverse in the case of low-efficiency regions). This finding confirms that wineries tend to operate in similar ways within each region, dragging nearby competitors to higher (or lower) levels of efficiency. This behavior is in line with the significance of spatially weighted regressors of supplies and services and the cost of raw materials, which means that competition in the access to (and conditions of) suppliers can influence inputs' pricing, availability, and quality, leading to gaps in a winery's productive efficiency.

Although lacking a systematic behavior pattern of location, it is possible to observe that firms located near more efficient competitors benefited from regional clustering, boosting their ability to reach higher efficiency rates and confirming the existence of spillover effects in some wine regions, such as Porto and Douro (particularly Port wine), Lisboa, Tejo, and Alentejo. On the other hand, firms located in low-density wine regions, such as Beira Interior or Setúbal and Palmela, with lower entrepreneurial sophistication (as Figure 2 suggests) struggled with regional clustering, since the availability of resources was limited. These findings confirm what is observed in traditional wine-producing countries, with different levels of wine regions clustering (i.e., from informal to innovative clusters (Migone and Howlett 2010)).

Additionally, to check the impact (either positive or negative) in the efficiency indicators from the space component, Equation (5) was re-estimated without the weighted variables related to space as a regular stochastic frontier model (non-weighted). Table 3 (above) includes the efficiency measures of this model as well as the difference of averages in comparison with the spatial weighted model. Complementary to this, Figure 5 displays the histograms of the frequencies of both overall efficiency scores, allowing an overview of possible differences due to the inclusion of the spatial effect in the model. 


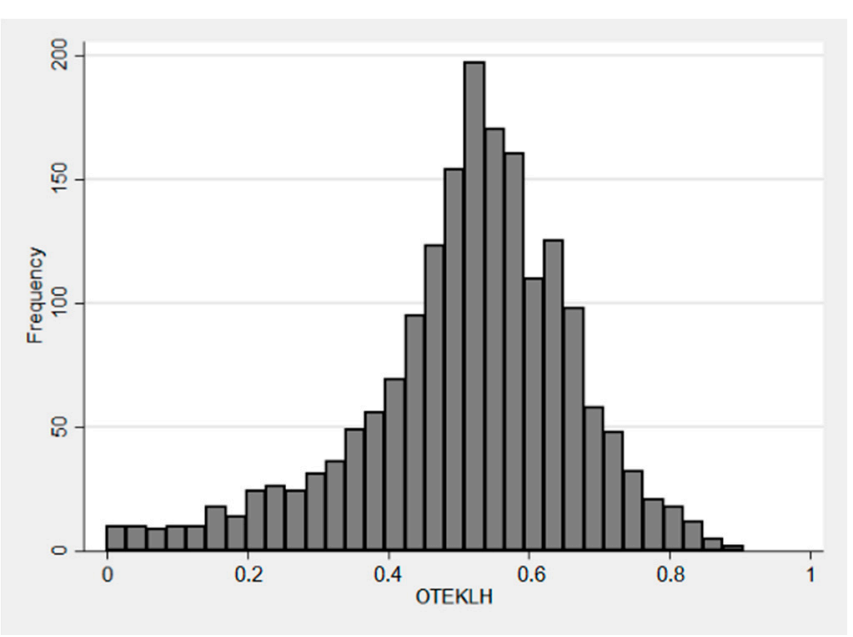

(a)

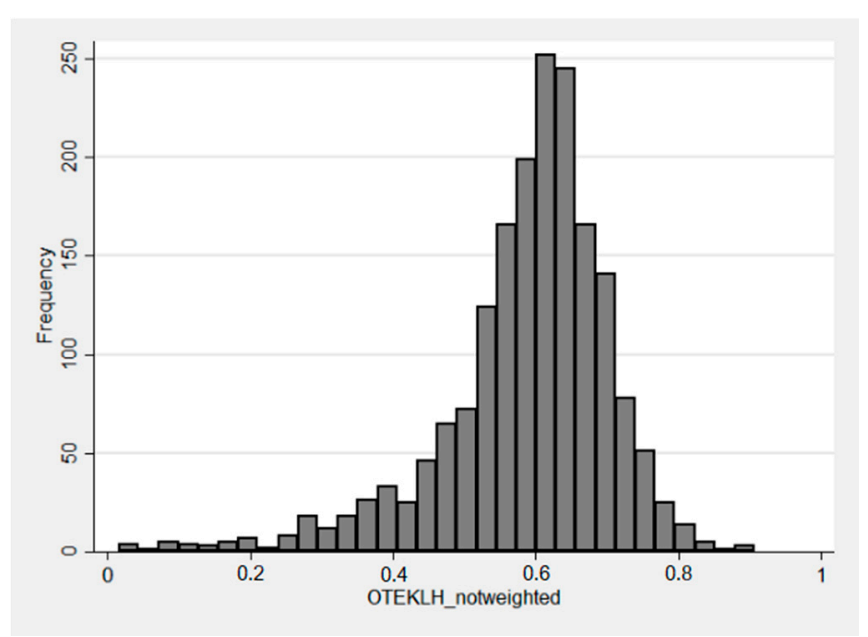

(b)

Figure 5. Comparison of overall efficiency frequencies. Source: own computation. (a) Overall efficiency with spatial effects. (b) Overall efficiency without spatial effects.

The results show that the spatial spillovers had, on average, a negative impact on wineries' productive efficiency. On average, the spatial component had a negative impact of $7.44 \%$ on the overall efficiency score. Moreover, the Kolmogorov-Smirnov test, with a value of 0.4997 and a significance level of $1 \%$, confirmed the rejection of the equality of frequency distributions, enhancing the differences between both scores. Together, these findings allow us to argue that in the Portuguese wine industry, firms have not yet reached an innovative level where the firms' management skills and institutional organizations can transfer knowledge and experience between wineries with positive productive efficiency gains, lacking innovative clusters, in line with the findings of Rebelo and Caldas (2013), and having negative consequences on the inputs of productivity and competitiveness.

Figure 6 demonstrates the linkage between the overall efficiency differences and labor productivity (ratio between the gross added value and employees). It shows that the regions where the difference was positive (i.e., where there were negative spatial effects in productive efficiency) roughly mimicked the geographical distribution of low-productivity areas, while regions with a negative difference (i.e., positive spatial effects) corresponded to high-productivity geographic locations. This inference is corroborated by a negative value $(-0.0967)$ and statistically significant Spearman's rank correlation between the differences in the efficiency scores and labor productivity.

Moreover, the Spearman's rank correlation of the differences in efficiency and firm size (employees) showed a negative and significant correlation at the $1 \%$ level $(-0.0674)$, which supports the argument that larger, highly productive firms can benefit from spatial effects, but conversely, smaller, less-productive firms struggle with the influence of location, which is in line with the findings of Vidoli et al. (2016).

These findings support that only in high labor productivity regions are the spatial spillovers positive, while in the lower productivity regions, the neighboring effects are negative. Again, this hints that to reach higher levels of efficiency, firms can benefit from knowledge sharing and R\&D cooperation, which will translate into greater productivity and competitiveness (Lorenzo et al. 2018), as occurs in innovative clusters.

In summation, the SAR, SEM, and SDM models confirmed the existence of spatial closeness relationships between wineries, as suggested in the work of Canello and Vidoli 2020. However, there was a random behavior and not a standardized pattern of clustering, which revealed the lack of regional clustering or the presence of mainly informal clusters, in line with the works of Rebelo and Caldas (2013) and Hogg and Rebelo's (2018) findings. Moreover, there is a link between location and efficiency (Bravo-Ureta et al. 2020; Outreville 2016), since the spatial neighboring effects were included in the SFSDM with the firms' productive efficiency change. 


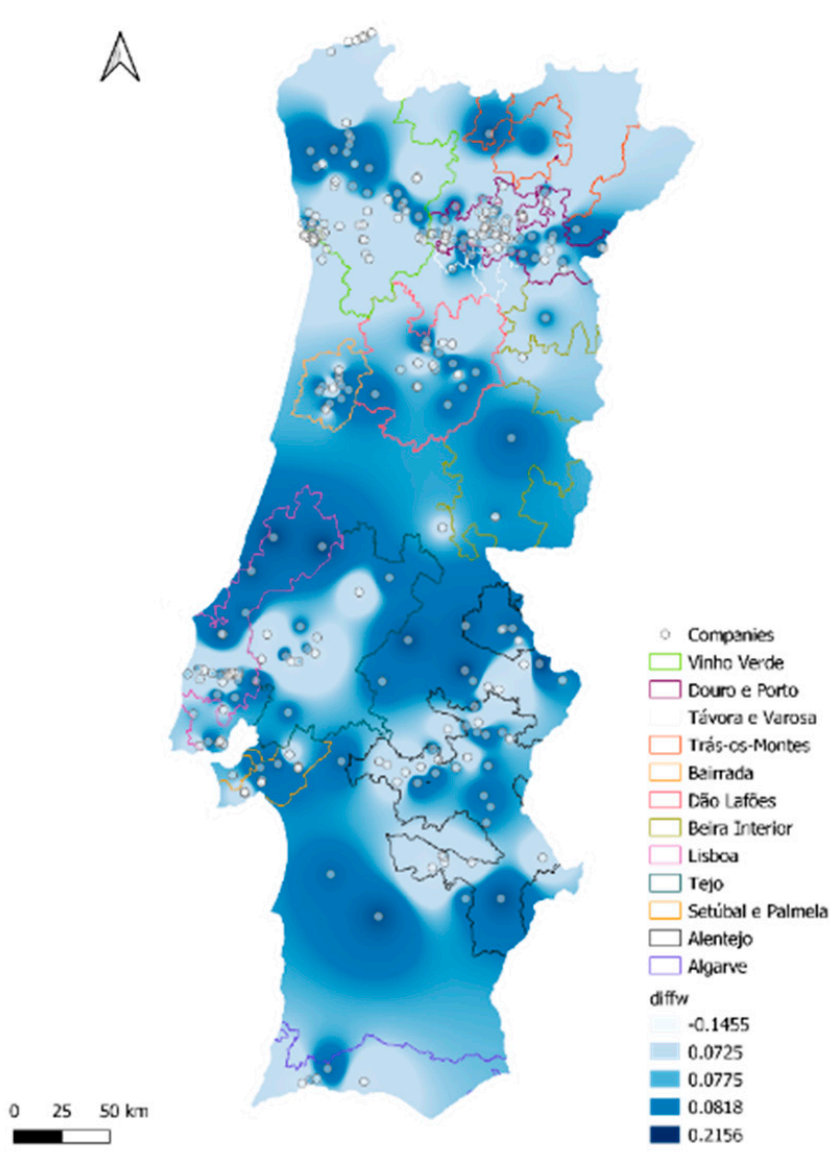

(a)

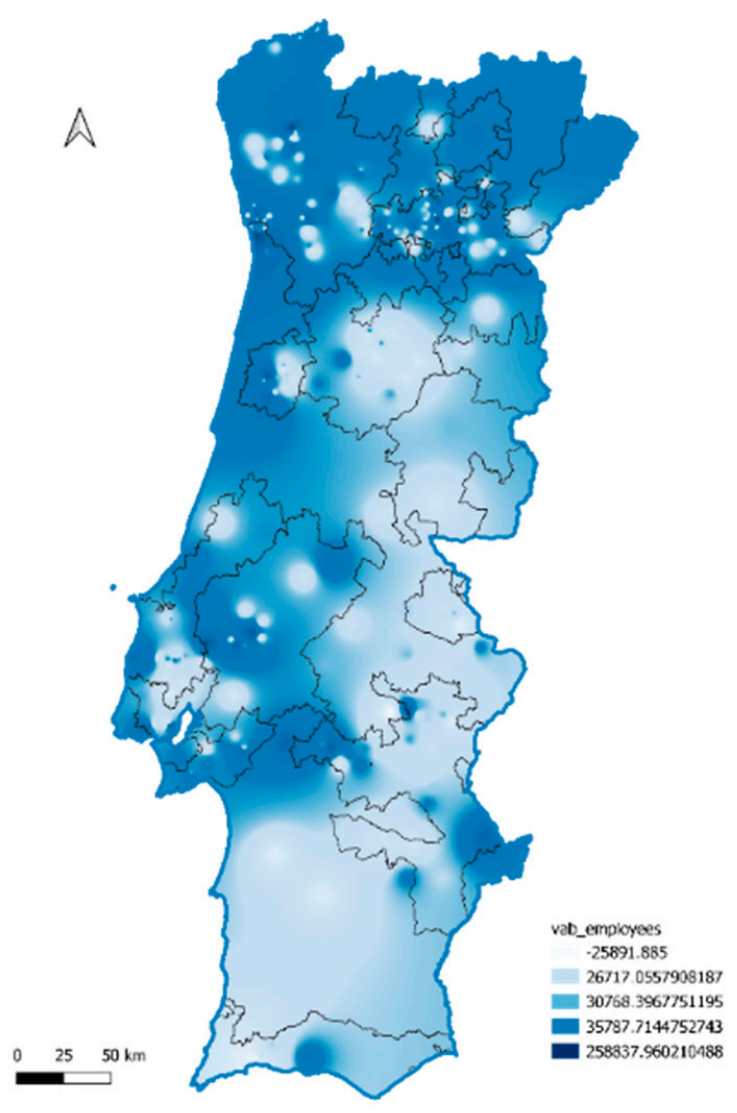

(b)

Figure 6. Differences in overall efficiency and labor productivity. Source: own elaboration. (a) Differences in overall efficiency. (b) Labor productivity.

\section{Conclusions}

In competitive market structures, companies are conditioned by the ability to manage the internal production organization, considering the impact of the external economic, institutional, and spatial environment both at the domestic and international levels. The analysis of these issues in terms of business performance calls for the computation of productive efficiency indices based on the SFA model. Specifically, the estimation of SFA panel data models allows for decomposing the productive efficiency into two components: (1) transient efficiency, resulting from entrepreneurial management decisions, and (2) persistent efficiency, ensuing from the environmental context within which firms operate. In industries closely linked to geographic location such as agri-foods, which includes wine-producing, the level of efficiency and therefore the competitiveness of the business depends on the firm's location, as this paper points out.

The results of this study underline the existence of spatial closeness relationships between wineries, albeit with a random behavior, not a standardized pattern of clustering, which reveals the lack of regional clustering or the presence of mainly informal clusters. Moreover, there is a link between the location and efficiency, with the scores of wineries' productive efficiency being affected. Specifically, the spatial spillover effects on productive efficiency are mostly negative, accounting for a 7.44 p.p. decrease in the overall productive efficiency. This means that the pull-down effects of the spatial spillovers were larger than the push-up effects, meaning that firms located near high-performance competitors did not benefit from generalized positive externalities deriving from innovation as well as easier access to the supply chain. These findings are in line with the fact that for historical, 
cultural, social, and economic reasons (Lains 2018), the Portuguese wine industry has not yet succeeded in deploying a business plan able to benefit from the synergies of all the wine regions. Positive externalities on productive efficiency were only verified in regions where there was already a concentration of high-productivity firms. This finding reflects the different maturity stages or economic development of the 12 Portuguese demarcated wine regions, mostly composed of a neophyte wine industrial base, which paved the way for the deployment of regional clusters.

The conclusions of this paper are in line with previous contributions, such as those of Vidoli et al. (2016), confirming the need for knowledge sharing and the development of formal networks in each wine region to foster the best practices in the whole industry (therefore improving overall efficiency). In addition, firms might choose their location to seek available resources (Outreville 2016), which was confirmed by this paper, since firms located in low-productivity regions struggle to reach higher levels of efficiency, and those that are located near high-productivity competitors can benefit from knowledge spillovers and access to suppliers, which results in enhanced managerial capabilities. Overall, we confirmed that the effect of the geographic location has a higher impact on SMEs (Vidoli et al. 2016).

This paper hints at the need to design specific spatial policies for each wine region in which all competitive advantages should be exploited, and on the other hand, the individual limitations should be mitigated, as suggested by Canello and Vidoli (2020), for the Italian wine industry. Furthermore, the relatively new competitive environment of the Portuguese wine industry calls for the development of policies that support collective added value for the industry as a means to reach competitive and industry-wide efficiency gains. These policies include measures such as the creation of research, development, and innovation platforms, logistic platforms, training of human resources with the appropriate skills, collective promotion in both internal and external markets, as well as creating conditions for the development of new supply chains and trade channels in these regions. All of this is translated into operational innovative clusters (Rebelo and Caldas 2013), aiming to (1) increase the size of firms and the number of critical actors, (2) introduce and spread a real culture of continuous innovations in the different phases of the wine chain, anticipating or provoking changes in market demand, and (3) amplify the cooperation and the networks between the different cluster players for a generalized and improved diffusion of knowledge and skills.

At the firm level, the majority of managers need to be aware that their winery's productive (transient) efficiency can increase significantly, which should imply the adoption of a benchmarking strategy that will be able to support decisions that contribute to improving the internal organization of the production process (improvement in the combination of inputs and output), marketing, control of the supply chain, and increasing in size. Simultaneously, the wineries should be active stakeholders in the creation of innovative clusters.

This research opens large avenues for future research in this topic, such as taking into consideration the assumptions of the dynamic nature of production technology and the introduction of new SF models accounting for possible endogeneity in the inputs. Additionally, since the weighted distance matrix is invariant, future research could benefit from using different distance measures, such as financial distance, to capture firm competitive dynamics.

Author Contributions: Conceptualization, J.R. and A.G.; methodology, S.F., A.G. and J.R.; software, S.F. and A.G.; validation, S.G. and J.R.; formal analysis, S.G., S.F., J.R. and A.G.; writing-original draft preparation, S.F., A.G., S.G. and J.R.; supervision, J.R. and S.G. All authors have read and agreed to the published version of the manuscript.

Funding: This study has received support from the FEDER-Interreg SUDOE project SOE3/P2/F0917, VINCI-Wine, Innovation and International Competitiveness, and the FCT-Portuguese Foundation for Science and Technology, project UIDB/SOC/04011/2020. 
Institutional Review Board Statement: Not applicable.

Informed Consent Statement: Not applicable.

Data Availability Statement: The data presented in this study are openly available at Samuel Faria (2021), "Dataset for Transient and persistent efficiency and spatial spillovers: Evidence from the Portuguese wine industry", Mendeley Data, V1, doi:10.17632/tcymhpxc86.1.

Conflicts of Interest: The authors declare no conflict of interest.

\section{Notes}

1 According to Kopp (1981), productive efficiency is defined as the ability of firms to produce a specified output at the minimum cost. Based on this definition, productive efficiency can be decomposed into two components: (1) technical efficiency, reflecting the physical efficiency of the input-output transformation, and (2) the allocative efficiency, reflecting the deviation from the optimal input allocation given their prices. Since this study estimates a production function, the productive efficiency corresponds to the technical efficiency, and therefore, both terms are used indistinctly throughout the paper.

2 Typically, two main specifications are used: the Cobb-Douglas (CD) and translog production functions (TL). The TL offers more flexibility than the $C D$, which is usually easier to estimate and works well when elasticities are constant over the sample (Pavelescu 2011).

3 In these studies, the division between firms that only produce and sell grapes (grape growers) and those whose main activity is the production and marketing of wine (wineries) is not always clear for whether or not they produce their own grapes. As is supported in the theoretical properties of production sets (Mas-Colell et al. 1995), this research focuses only on wineries to assure technology homogeneity.

4 "Quadros do setor" database, assessed in 1 December 2020, which can be found in https:/ / www.bportugal.pt/QS/qsweb/ Dashboards. This is a legal registration which considers firms constituted. Since some of them are not in activity, the number of wineries with accounting information is annually lower.

5 Since we are in the presence of a short time span where the input and output real prices remained stable, neutral technological progress is assumed (Oosthuizen and Conradie 2018).

6 According to the level of integration within the wine supply chain, there are three groups of firms: (1) grape growers, who produce and sell grapes; (2) merchants, who sell wine but are not producers; and (3) wineries that produce and sell wine. This research only includes the third group.

$7 \quad$ Moran's I (Upton and Fingleton 1985) is a statistical measure that signals spatial autocorrelation among neighboring observations. This statistic can be applied to a specific variable (usually the dependent variable) or to the error term. If the value is statistically non-significant (equal to zero), there is no spatial autocorrelation between observations. If it is positive and statistically significant, it shows autocorrelation between observations in the same category (i.e., there is clustering in high values and low values). If it is negative and statistically significant, the autocorrelation is negative, meaning that there is spatial dispersion (high values repel high values and low values repel low values).

8 The result $\left[\right.$ LR Chi2 $(16)=235.79^{* * *}$ ] points to the rejection of the null hypothesis (all second order parameters together are equal to zero), and thus the translog is preferred.

9 The presence of time effects is assessed through the inclusion of the " $\mathrm{t}$ " variable in the production function. In the first step, an RE regression that also included time dummies was estimated. However, multicollinearity with the constant error term was identified, and the reported model dropped such a hypothesis.

\section{References}

Acosta, Alejandro, and Luis A. de los Santos-Montero. 2019. What is driving livestock total factor productivity change? A persistent and transient efficiency analysis. Global Food Security 21: 1-12. [CrossRef]

Agasisti, Tommaso, and Sabine Gralka. 2019. The transient and persistent efficiency of Italian and German universities: A stochastic frontier analysis. Applied Economics 51: 5012-30. [CrossRef]

Aigner, Dennis, C. A. Knox Lovell, and Peter Schmidt. 1977. Formulation and estimation of stochastic frontier production function models. Journal of Econometrics 6: 21-37. [CrossRef]

Alem, Habtamu. 2018. Effects of model specification, short-run, and long-run inefficiency: An empirical analysis of stochastic frontier models. Agricultural Economics (Zemědělská Ekonomika) 64: 508-16. [CrossRef]

Aparicio, Juan, Lidia Ortiz, Jesus Pastor, and Jon M. Zabala-Iturriagagoitia. 2020. Introducing cross-productivity: A new approach for ranking productive units over time in Data Envelopment Analysis. Computers and Industrial Engineering. [CrossRef]

Areal, Francisco José, Kelvin Balcombe, and Richard Tiffin. 2012. Integrating spatial dependence into Stochastic Frontier Analysis. Agriculture and Resource Economics 56: 521-541. [CrossRef]

Astuti, Alfira, Ir Setiawan, Ismaini Zain, and Jerry Dwi T. Purnomo. 2020. A Review of Panel Data on Spatial Econometrics Models. Journal of Physics: Conference Series 1490. [CrossRef] 
Barrios, Ernel B., and Rouselle F. Lavado. 2010. Spatial Stochastic Frontier Models. Manila: Philippine Institute for Development Studies.

Battese, George E., and Tim J. Coelli. 1988. Prediction of firm-level technical efficiencies with a generalized frontier production function and panel data. Journal of Econometrics 38: 387-99. [CrossRef]

Battese, George E., and Tim J. Coelli. 1992. Frontier production functions, technical efficiency and panel data: With application to paddy farmers in India. Journal of Productivity Analysis 3: 153-69. [CrossRef]

Battese, George E., and Tim J. Coelli. 1995. A model for technical inefficiency effects in a stochastic frontier production function for panel data. Empirical Economics 20: 325-32. [CrossRef]

Behmiri, Niaz Bashiri, João Rebelo, Sofia Gouveia, and Patrícia António. 2019. Firm characteristics and export performance in Portuguese wine firms. International Journal of Wine Business Research 31: 419-40. [CrossRef]

Bravo-Ureta, Boris E., Víctor H. Moreira, Javier L. Troncoso, and Alan Wall. 2020. Plot-level technical efficiency accounting for farm-level effects: Evidence from Chilean wine grape producers. Agricultural Economics 51: 811-24. [CrossRef]

Breusch, Trevor S., and Adrian R. Pagan. 1980. The Lagrange Multiplier Test and its Applications to Model Specification in Econometrics. The Review of Economic Studies 47: 239-53. [CrossRef]

Canello, Jacopo, and Francesco Vidoli. 2020. Investigating space-time patterns of regional industrial resilience through a micro-level approach: An application to the Italian wine industry. Journal of Regional Science 60: 653-76. [CrossRef]

Colombi, Roberto, Gianmaria Martini, and Giorgio Vittadini. 2011. A Stochastic Frontier Model with Short-Run and Lon-Run Inefficiency Random-Effects. (Working Paper no. 11001). Bergamo: Department of Economics and Technology Management, University of Bergamo.

Colombi, Roberto, Subal Kumbhakar, and Gianmaria Martini. 2014. Closed-skew normality in stochastic frontiers with individual effects and long/short-run efficiency. Journal of Productivity Analysis 42: 123-36. [CrossRef]

Conradie, Beatrice, Graham Cookson, and Colin Thirtle. 2006. Efficiency and farm size in Western Cape grape production: Pooling small datasets. South African Journal of Economics 74: 334-43. [CrossRef]

Cusmano, Lucia, Andrea Morrison, and Roberta Rabellotti. 2010. Catching up trajectories in the wine sector: A comparative study of Chile, Italy, and South Africa. World Development 38: 1588-602. [CrossRef]

Druska, Viliam, and William Horrace. 2004. Generalized moments estimation for spatial panel data: Indonesian rice farming. American Journal of Agricultural Economics 86: 185-98. [CrossRef]

Faria, Samuel, Lina Lourenço-Gomes, Sofia Gouveia, and João Rebelo. 2020. Economic performance of the Portuguese wine industry: A microeconometric analysis. Journal of Wine Research 31: 283-300. [CrossRef]

Filippini, Massimo, and William Greene. 2015. Persistent and transient productive inefficiency: A maximum simulated likelihood approach. Journal of Productivity Analysis 45: 187-96. [CrossRef]

Fusco, Elisa, and Francesco Vidoli. 2013. Spatial stochastic Frontier models: Controlling spatial global and local heterogeneity. International Review of Applied Economics 27: 679-94. [CrossRef]

Glass, Anthony, and Karligash Kenjegalieva. 2019. A spatial productivity index in the presence of efficiency spillovers: Evidence for U.S. banks 1992-2015. European Journal of Operational Research. [CrossRef]

Glass, Anthony, Karligash Kenjegalieva, and Robin C. Sickles. 2016. A spatial autoregressive stochastic frontier model for panel data with asymmetric efficiency spillovers. Journal of Econometrics 190: 289-300. [CrossRef]

Greene, William. 2005. Reconsidering heterogeneity in panel data estimators of the stochastic frontier model. Journal of Econometrics 126: 269-303. [CrossRef]

Greene, William. 2008. The Econometric Approach to Efficiency Analysis. The Measurement of Productive Efficiency and Productivity Change 4: 92-250. [CrossRef]

Guedes, Alexandre, and João Rebelo. 2019. Merging wine and tourism-related services: Evidence from the Douro (Portugal) Wine Region. Journal of Wine Research 30: 259-74. [CrossRef]

Haini, Hazwan. 2020. Spatial productivity and efficiency spillovers in the presence of transient and persistent efficiency: Evidence from China's provinces. Cogent Economics and Finance 8. [CrossRef]

Hogg, Tim, and João Rebelo. 2018. Rumo Estratégico Para os Vinhos do Douro e Porto. Vila Real: Universidade de Trás-os-Montes e Alto Douro (UTAD), ISBN 978-989-704-344-4.

Instituto da Vinha e do Vinho. 2019. Exportação/expedição de vinhos, série 2010 a 2019. Available online: https: / / www.ivv.gov.pt/ np4/9334.html (accessed on 5 January 2021).

Jondrow, James, C. A. Knox Lovell, Ivan S. Materov, and Peter Schmidt. 1982. On the estimation of technical inefficiency in the stochastic frontier production function model. Journal of Econometrics 19: 233-38. [CrossRef]

Kallas, Zein, and Fatima Lambarra. 2010. Technical efficiency and firm exit in the wine and meat sector: Policy implications. New Medit 9: 25-31.

Kopp, Raymond J. 1981. The Measurement of Productive Efficiency: A Reconsideration. Quarterly Journal of Economics 96: 477-503. [CrossRef]

Kumbhakar, Subal C. 1990. Production frontiers, panel data, and time-varying technical inefficiency. Journal of Econometrics 46: 201-11. [CrossRef]

Kumbhakar, Subal C., and Almas Heshmati. 1995. Efficiency Measurement in Swedish Dairy Farms: An Application of Rotating Panel Data. American Journal of Agricultural Economics 77: 660-74. [CrossRef] 
Kumbhakar, Subal, Christopher F. Parameter, and Valentin Zelenyuk. 2018. Stochastic Frontier Analysis: Foundations and Advances. (Working Paper No. WP02/2018). St Lucia: School of Economics University of Queensland, Available online: https:/ / economics. uq.edu.au/files/5022/WP022018.pdf (accessed on 13 August 2021).

Kumbhakar, Subal C., Gudbrand Lien, and J. Brian Hardaker. 2014. Technical efficiency in competing panel data models: A study of Norwegian grain farming. Journal of Productivity Analysis 41: 321-37. [CrossRef]

Kumbhakar, Subal, Hung-Jen Wang, and Alan P. Horncastle. 2015. A Practitioner's Guide to Stochastic Frontier Analysis Using Stata. Cambridge: Cambridge University Press.

Kutlu, Levent, and Usha Nair-Reichert. 2019. Agglomeration effects and spatial spillovers in efficiency analysis: A distribution-free methodology. Regional Studies 53: 1565-74. [CrossRef]

Lains, Pedro. 2018. Portugal. In Wine Globalization: A New Comparative History. Edited by Kym Anderson and Vicente Pinilla. Cambridge: Cambridge University Press, pp. 178-207. [CrossRef]

Lorenzo, Juan Ramón Ferrer, María Teresa Maza Rubio, and Silvia Abella Garcés. 2018. The competitive advantage in business, capabilities and strategy. What general performance factors are found in the Spanish wine industry? Wine Economics and Policy. [CrossRef]

Macedo, Anthony, Sofia Gouveia, and João Rebelo. 2019. Horizontal differentiation and determinants of wine exports: Evidence from Portugal. Journal of Wine Economics 15: 163-80. [CrossRef]

Marta-Costa, Ana, Vitor Martinho, and Micael Santos. 2017. Productive efficiency of Portuguese vineyard regions. Regional Science Inquiry 9: 97-107.

Martínez-Victoria, María Carmen, María Luz Maté-Sánchez-Val, and Alfons Oude Lansink. 2019. Spatial dynamic analysis of productivity growth of agri-food companies. Agricultural Economics 50: 315-27. [CrossRef]

Mas-Colell, Andreu, Michael D. Whinston, and Jerry R. Green. 1995. Microeconomic Theory. Oxford: Oxford University Press.

Meeusen, Wim, and Julien van Den Broeck. 1977. Efficiency Estimation from Cobb-Douglas Production Functions with Composed Error. International Economic Review 18: 435-44. [CrossRef]

Migone, Andrea, and Michael Howlett. 2010. Comparative Networks and Clusters in the Wine Industry. (AAWE Working Paper No. 62). New York: American Association of Wine Economists, Available online: http:/ / www.wineeconomics.org (accessed on 14 January 2021).

Moreira, Víctor H., Javier Luis Troncoso, and Boris Bravo-Ureta. 2011. Technical Efficiency for a Sample of Chilean Wine Grape Producers: A Stochastic Production Frontier Analysis. Ciencia e Investigación Agraria 38: 321-29. [CrossRef]

Morrison, Andrea, and Roberta Rabellotti. 2017. Gradual catch up and enduring leadership in the global wine industry. Research Policy 46: 417-30. [CrossRef]

Oosthuizen, Morné, and Beatrice Conradie. 2018. Preliminary Indications of the Negative Effects of Climate Change on the West Coast Wine Industry's Performance. Paper presented at Agricultural Economics Association of South Africa (AESA), 2018 Annual Conference, Cape Town, South Africa, September 25-27.

Outreville, Jean-François. 2016. Foreign affiliates of the multinational firms in the wine and spirits industry: Location-specific advantages and cultural distance. International Journal of Economics and Business Research 12: 274-94. [CrossRef]

Pavelescu, Florin-Marius. 2011. Some aspects of the translog production function estimation. Romanian Journal of Economics 32: 41. [CrossRef]

Pede, Valerien, Francisco J. Areal, Alphonse Singbo, Justin McKinley, and Kei Kajisa. 2018. Spatial dependency and technical efficiency: An application of a Bayesian stochastic frontier model to irrigated and rainfed rice farmers in Bohol, Philippines. Agricultural Economics 49: 301-12. [CrossRef]

Pham, Manh D., Leopold Simar, and Valentin Zelenyuk. 2019. Statistical Inference for Aggregation of Malmquist Productivity Indices. (Working Paper No. WP082019). St Lucia: School of Economics, University of Queensland.

Pitt, Mark M., and Lung-Fei Lee. 1981. The measurement and sources of technical inefficiency in the Indonesian weaving industry. Journal of Development Economics 9: 43-64. [CrossRef]

Pokharel, Shree B. 2018. Wine Industry Campaign Contributions and Wine Excise Taxes: Evidence from U.S. States. Journal of Wine Economics 13: 3-19. [CrossRef]

Porter, Michael E. 2000. Location, competition and economic development: Local clusters in a global economy. Economic Development Quartely 14: 15-34. [CrossRef]

Rebelo, João, and José Vaz Caldas. 2013. The Douro wine region: A cluster approach. Journal of Wine Research 24: 19-37. [CrossRef]

Rebelo, João, and Dorli Muhr. 2012. Innovation in wine SMEs: The Douro Boys informal network. Studies in Agricultural Economics 114: 111-17. [CrossRef]

Tóth, József, and Péter B. K. Gá. 2014. Is the New Wine World more efficient? Factors influencing technical efficiency of wine production. Studies in Agricultural Economics 116: 95-99. [CrossRef]

Tsukamoto, Takashiro. 2019. A spatial autoregressive stochastic frontier model for panel data incorporating a model of technical inefficiency. Japan and the World Economy 50: 66-77. [CrossRef]

Ugaglia, Aldeline Alonso, Jean-Marie Cardebat, and Alessandro Corsi. 2019. The Palgrave Handbook of Wine Industry Economics. Berlin/Heidelberg: Springer.

Upton, Graham, and Bernard Fingleton. 1985. Spatial Data Analysis by Example. Volume 1: Point Pattern and Quantitative Data. Hoboken: John W \& Sons Ltd. 
Urso, Arturo, Giuseppe Timpanaro, Grancesco Caracciolo, and Luigi Cembalo. 2018. Efficiency analysis of Italian wine producers. Wine Economics and Policy 7: 3-12. [CrossRef]

Vidoli, Francesco, Concetta Cardillo, Elisa Fusco, and Jacopo Canello. 2016. Spatial nonstationarity in the stochastic frontier model: An application to the Italian wine industry. Regional Science and Urban Economics 61: 153-64. [CrossRef]

Zhao, Shunan, Man Jin, and Subal C. Kumbhakar. 2020. Estimation of firm productivity in the presence of spillovers and common shocks. Empirical Economics. [CrossRef] 